\title{
Resistance to freshwater exposure in White Sea Littorina spp. I: Anaerobic metabolism and energetics
}

Accepted: 4 October 1999

\begin{abstract}
Anaerobic metabolism and changes in the osmotic concentration of extravisceral fluid were studied in the White Sea periwinkles (Littorina littorea, Littorina saxatilis and Littorina obtusata) during freshwater exposure. Resistance to hypoosmotic stress increased in the order: L. obtusata $<$ L. saxatilis $<$ L. littorea. Our data suggest that osmotic shock is not a primary reason for mortality of the periwinkles under these conditions. During environmental anaerobiosis, considerable succinate accumulation (up to $10-19 \mu \mathrm{mol} \mathrm{g}{ }^{-1}$ wet weight), and depletion of phosphagen and ATP pools were found in the studied species. Other metabolic end products (alanopine, strombine, lactate, acetate or propionate) were not detected. Succinate accumulation and net ATP breakdown were the fastest in the least resistant species, L. obtusata, and slowest in the most resistant, L. littorea. Rate of ATP turnover decreased during freshwater exposure in L. littorea and L. saxatilis, but not in L. obtusata. Our data suggest that differential resistance of three studied Littorina spp. to extreme hypoosmotic stress may be related to their different abilities to reduce metabolic rate and ATP turnover during sustained anoxia. Species-specific variations in
\end{abstract}

Communicated by G. Heldmaier

\section{M. Sokolova}

White Sea Biological Station,

Zoological Institute of Russian Academy of Sciences,

Universitetskaya nab., 1,

199034 St. Petersburg, Russia

e-mail: Inna@sokolzoo.spb.su

Tel.: + 7-812-1140097; Fax: + 7-812-1140444

C. Bock · H.-O. Pörtner

Alfred-Wegener-Institute for Polar and Marine Research,

Ecology and Ecophysiology,

Columbusstrasse 30 ,

27568, Bremerhaven, Germany

e-mail: HPoertner@awi-bremerhaven.de,

CBock@awi-bremerhaven.de

Fax: + 49-0471-4831149 anaerobic capacity of Littorina spp. are discussed in relation to their vertical distribution, size and ecology.

Key words Salinity stress - Resistance adaptations · Anaerobic metabolism - ATP turnover - Littorina spp.

Abbreviations $A D P$ adenosine- $5^{\prime}$-diphosphate $\cdot A E C$ adenylate energy charge $\cdot A M P$ adenosine- $5^{\prime}$ monophosphate $\cdot A T P$ adenosine-5'-triphosphate $\cdot \operatorname{Arg}$ L-arginine $\cdot A W I$ Alfred-Wegener-Institute for Polar and Marine Research $\cdot d G / d \xi$ Gibbs free energy change $\cdot E D T A$ ethylenediaminetetraacetic acid $\cdot E F$ extravisceral fluid - HPLC High Performance Liquid Chromatography $\cdot H S D$ honestly significant difference $\cdot \dot{M}_{A T P}$ ATP turnover rate $\cdot N T A$ nitrilotriacetic acid $P C A$ perchloric acid $\cdot P_{i}$ inorganic phosphate $\cdot P L A$ phospho-L-arginine $\cdot R_{P L A}$ relative amount of phosphagen $\cdot R_{\mathrm{ST}}$ standardised respiration rate

\section{Introduction}

Salinity is an important environmental factor influencing various life characteristics of marine animals, including molluscs. Adaptation of marine molluscs to changes in salinity is achieved through two different systems which are used alternatively depending on the degree of the environmental disturbance (e.g. Kinne 1964; Berger 1986; Berger and Kharasova 1997). If salinity changes moderately, so-called capacity adaptations play a major part in adjusting to the new osmotic conditions. In marine molluscs, these adaptations involve isoosmotic cell volume regulation through, for example, shifts of intracellular free amino acid and inorganic ion concentrations (e.g. Lockwood 1976; Natochin et al. 1979; Taylor and Andrews 1988; Hawkins and Hilbish 1992), and changes of oxygen consumption rates during salinity acclimation (Kinne 1971; Berger 1986). Capacity adaptations typically result in adjustments which ensure performance of the most 
important life functions and potentially unlimited survival in the new osmotic environment. In contrast, if environmental salinity strongly deviates from the optimum, resistance adaptations are evoked. In marine shelled gastropods these are so called escape responses (see review in Kinne 1971; Lockwood 1976; Berger 1986). Under conditions of extremely low or high salinity, snails withdraw into the shell and isolate themselves inside by tight closure of the shell aperture with their operculum. This behavioural response greatly reduces water and salt exchange between the internal medium of the animal and the unfavourable environment (Avens and Sleigh 1965; Rumsey 1973; Berger 1986). A similar response is typical for bivalves (Kinne 1971; Lockwood 1976). However, the resistance response provides only limited survival of the organism, and if the period of extreme salinity stress persists, considerable mortality is observed.

Reasons for the mortality of shelled gastropods and bivalves under conditions of extreme salinity have long been debated in the literature (e.g. Akberali et al. 1977; Berger 1986). Principally, two different causes of mortality have been suggested: (1) osmotic shock due to the gradual gain or loss of salts and/or water in a strongly hyper- or hypoosmotic medium, and (2) unfavourable changes of the acid-base and/or energy status of the animal due to sustained environmental anaerobiosis in the isolated state. There are some data suggesting that the first mechanism is of less (if any) importance in some intertidal molluses (Littorina saxatilis, Mytilus edulis, Berger 1980) and the freshwater bivalve Anodonta grandis (Byrne and McMahon 1991), whereas in Mya arenaria and Macoma baltica the osmotic shock due to marked dilution of the internal milieu was named among the probable causes of the mortality onset (Golikov and Smirnova 1974; Khlebovich 1974; Berger 1980). At the same time, there is no evidence for or against the second hypothesis, as there are no data on changes of the acidbase and/or energy status of the organism during exposure to extreme salinities.

Three closely related gastropod species - Littorina saxatilis, Littorina obtusata and Littorina littorea - are common inhabitants of White Sea intertidal and upper subtidal zones. The periwinkles are convenient objects for the study of resistance adaptations to extremely low salinities. L. saxatilis inhabits the high intertidal zone where it spends prolonged periods of air exposure in a state of dormancy (McMahon 1990), L. obtusata lives in the middle and low littoral, mostly in the brown macrophyte (Fucus vesiculosus and Ascophyllum nodosum) canopy, and L. littorea occupies lower intertidal and subtidal horizons. In the White Sea, Littorina spp. may experience prolonged periods of extreme hypoosmotic stress, especially during spring ice-melting when surface water salinity can drop drastically (down to $2 \%$ ) for as long as a fortnight (Babkov and Lukanin 1985). These species exhibit rather high, species-specific differences in the capability to survive prolonged periods in an extremely hypoosmotic medium (Berger 1986). This allows correlation of changes in anaerobic metabolic rate and energy status with differential survival during prolonged periods of hypoosmotic exposure and to suggest the primary mechanisms of mortality (and/or resistance) under such conditions.

The aim of our study was to investigate anaerobic metabolism in the White Sea periwinkles L. littorea, L. saxatilis and L. obtusata during extreme hypoosmotic stress. We followed the time courses of mortality, anaerobic end-product accumulation and changes in the parameters of energy status and also analysed changes in the osmotic concentration of the extravisceral fluid (EF) in L. littorea during prolonged freshwater exposure. Additionally, we compared the routine metabolic rates under normoxic control conditions in the three studied species.

This investigation intended to answer the following questions:

1. Could osmotic shock alone account for the mortality onset in periwinkles during freshwater exposure?

2. Are there any species-specific differences in the time courses of anaerobic end-product accumulation and changes of intracellular energy status of the periwinkles during prolonged freshwater exposure?

3. Do anaerobic and aerobic metabolic rates (the latter as assessed by routine oxygen consumption) differ in the studied Littorina spp.?

4. Does differential resistance to fresh water correlate with variations in the rate of anaerobic metabolism (i.e. rate of end-product accumulation) and ATP turnover in the periwinkles?

\section{Materials and methods}

Sampling of the periwinkles

Sampling was performed in July 1996 and August 1997 in the Chupa Inlet of Kandalaksha Bay in the White Sea $\left(66^{\circ} 20^{\prime} \mathrm{N}\right.$, $33^{\circ} 40^{\prime} \mathrm{E}$ ). Water temperature in the field was $10-15^{\circ} \mathrm{C}$, salinity $25-$ $27 \%$. L. saxatilis and L. obtusata were collected from the macrophyte belt and gravel patches in the middle and lower intertidal zone, and L. littorea was sampled from stones and pebbles in the lower intertidal to upper subtidal zones. Prior to incubation all snails were kept for $2-5$ days in recirculating aquaria with natural sea water (salinity $26-27 \%$ ) at $7.7 \pm 0.6{ }^{\circ} \mathrm{C}$. Aquaria were equipped with gravel bottom filters and air-pumps. Only adult snails were used for the experiments. Shell diameters varied between $7-10 \mathrm{~mm}$ in L. saxatilis, $8-11 \mathrm{~mm}$ in L. obtusata and $22-26 \mathrm{~mm}$ in L. littorea.

\section{Respiration rate}

Measurements of routine respiration rate were performed by closed system respirometry (Lyzen et al. 1990). Animals were taken out of the aquaria, placed individually into air-tight glass bottles halffilled with natural sea water (salinity $26-27 \%$, temperature $7.7 \pm$ $0.6{ }^{\circ} \mathrm{C}$ ) and left for $30 \mathrm{~min}$ to reduce the effect of handling. After this, the bottles were carefully drained using a thin plastic tube, refilled with sea water of the same salinity and temperature and tightly closed. Additionally, 2-3 control bottles of the same size (without snails) were filled with sea water. Bottles were exposed at unchanged temperature for $8 \mathrm{~h}$ (L. saxatilis and L. obtusata) or $4 \mathrm{~h}$ 
(L. littorea). After the specified exposure periods, oxygen concentration was measured in experimental and control bottles to the nearest $0.01 \mathrm{mg} \mathrm{l}^{-1}$ using an OXY-320 oxygen meter (WTW, Germany). The oxygen content in the experimental bottles never fell by more than $25-30 \%$ below control levels.

After the measurements, snails were taken out of the bottles and rapidly killed in boiling water. Soft tissues were removed, blotted and weighed to the nearest $0.5 \mathrm{mg}$. The presence of trematodes (microphallids of the "pygmaeus" group) was recorded under a binocular microscope. Respiration rates were calculated as $\mu \mathrm{g} \mathrm{O}_{2}$ consumed by a snail per hour per gram wet tissue weight. Average wet tissue weight was $143.4 \pm 7.3 \mathrm{mg}$ in L. obtusata $(n=18)$, $138.9 \pm 6.2 \mathrm{mg}$ in L. saxatilis $(n=19)$ and $951.0 \pm 41.4 \mathrm{mg}$ in L. littorea $(n=19)$.

It has been demonstrated that infection by the microphallids of the "pygmaeus" group did not influence respiration rate of L. saxatilis and L. obtusata (Lyzen et al. 1990; Sokolova 1997). Preliminary analysis showed that this was also the case with the studied periwinkles. Thus, we pooled data for infected and uninfected snails for subsequent comparisons.

\section{Incubation procedure}

Experimental incubation and tissue sampling were performed at the White Sea Biological Station (Cape Kartesh, White Sea). Further analyses were carried out at the Alfred-Wegener-Institute for Polar and Marine Research (AWI, Bremerhaven, Germany). Incubation temperature was $7.7 \pm 0.6^{\circ} \mathrm{C}$. Control animals were incubated in aquaria with well-aerated natural sea water of $26-27 \%$. Experimental animals were placed in plastic trays and covered with plenty of natural fresh water from the nearby Krivoye Lake, a typical lake for the Karelian shore of the White Sea characterised with very low inorganic ion concentrations (Naumov, personal communication). The water in incubation trays was changed daily. After specified exposure periods a number of snails were removed from the tray. The snails which responded by withdrawing the body deeper into the shell after being poked by a needle inserted under the operculum, were scored as alive and used further for tissue and EF sampling. Animals were dissected and rapidly examined for the presence of trematode parasites. Infected individuals were discarded. In the uninfected snails the foot was quickly ectomised and immediately frozen in liquid nitrogen. Tissue samples were stored in liquid nitrogen.

In L. littorea, a sample of EF (ca. $100 \mu \mathrm{l}$ ) was taken before dissection, by means of a syringe inserted into the extravisceral cavity between shell and body. Samples of the EF were centrifuged for 3-4 min at $13500 \mathrm{rpm}$, the supernatant collected and stored at $-20{ }^{\circ} \mathrm{C}$. The remaining animals were taken out of the tray and placed into sea water $(26-27 \%$ ). After $2 \mathrm{~h}$ these sub-samples were examined for the presence of dead snails which did not resume activity.

\section{Measurement of EF osmolarity}

The osmolarity of the EF ( $\mathrm{mOsmol} \mathrm{kg}{ }^{-1}$ ) was measured at the AWI by a Wescor vapour pressure osmometer (Wescor, Logan, Utah). For each sample, three to four measurements were made, and the mean value calculated. To transform osmolarity into salinity units, six concentrations of artificial sea water $(0,10,15,20,25$ and $30 \%$ ) were prepared using Milli-Q deionized water and artificial sea salt (Tropic Marin, Germany), and their osmolarity was measured. Values of the EF osmolarity were transformed into salinity units by interpolation using the regression line for artificial sea water.

\section{Metabolite determination}

For the determination of metabolite concentrations, foot tissue was powdered with mortar and pestle under liquid nitrogen. In the case of $L$. littorea, each extraction was made from the tissue of a single specimen; for the smaller L. saxatilis and L. obtusata, tissues from
8-12 animals were pooled. Ca. $300 \mathrm{mg}$ of tissue powder were added to an excess $(5 \times)$ volume of pre-cooled $0.6 \mathrm{~mol} \cdot 1^{-1}$ perchloric acid (PCA) and homogenised. Precipitated protein was removed by centrifugation. The extract was neutralised with $5 \mathrm{mmol} \cdot \mathrm{l}^{-1}$ potassium hydroxide to $\mathrm{pH}$ 7.0-7.5. Precipitated potassium perchloride was removed by a second centrifugation. Extracts were stored at $-80{ }^{\circ} \mathrm{C}$.

In a second set of samples adenylate extraction by PCA was maximised by the addition of EDTA (also see Results). Foot tissue of $L$. littorea collected under control conditions and after 3 days of freshwater exposure was ground with mortar and pestle under liquid nitrogen. The tissue powder was divided into two approximately equal portions which were extracted with $0.6 \mathrm{~mol}^{-1} 1^{-1} \mathrm{PCA}$ or $0.6 \mathrm{~mol} \cdot 1^{-1}$ PCA with $10 \mathrm{mmol} \cdot 1^{-1}$ EDTA as described above.

Concentrations of succinate, lactate, acetate and propionate in PCA extracts were measured according to a method modified from Hardewig et al. (1991). Fatty acids were separated on an ion exclusion column (Dionex ICE-AS 1) at a flow rate of $1 \mathrm{ml} \mathrm{min}{ }^{-1}$ and $40{ }^{\circ} \mathrm{C}$ with $0.125 \mathrm{mmol} \cdot 1^{-1}$ heptafluorobutyric acid used as an eluent. Peaks were monitored with a conductivity detector. A micro membrane suppressor (Dionex AMMS-ICE) was used to decrease background conductivity. In some extracts, succinate and L-lactate were also determined spectrophotometrically using enzymatic tests (Bergmeyer 1985). Concentrations of the metabolites obtained by either method were in close agreement.

Alanopine and strombine were measured by cation exchange chromatography. Separation was carried out at $45^{\circ} \mathrm{C}$ on an Interaction ARH-601 column for aromatic acids (ICT-ASS-Chemicals, Bad Homburg, Germany); a solution of $1 \mathrm{mN} \mathrm{H}_{2} \mathrm{SO}_{4}$ was used as an eluent. A conductivity detector was utilised to monitor the peaks. Standard opine solutions were prepared according to a method modified from Siegmund and Grieshaber (1983).

Concentrations of AMP, ADP and ATP were measured using an HPLC system (Beckman Instruments, USA) and Spherisorb C18 column (Latek, Germany) according to a method modified from Fischer (1995). Separation was carried out at a flow rate of $0.8 \mathrm{ml} \mathrm{min}{ }^{-1}$ using the mobile phase of $2 \mathrm{mmol} \cdot \mathrm{l}^{-1} 11$-aminoundecanoic acid in $25 \mathrm{mmol} \cdot 1^{-1}$ phosphate buffer with $8 \%(\mathrm{v} / \mathrm{v})$ methanol $(\mathrm{pH}=6)$. Peaks were monitored at $210 \mathrm{~nm}$ using a Diode Array Detector Module 168 (System Gold, Beckman Instruments, Munich, Germany).

Concentrations of phospho-L-arginine (PLA) and L-arginine (Arg) were assayed spectrophotometrically using the enzymatic test described by Grieshaber et al. (1978). Octopine dehydrogenase for these determinations was purified from the adductor muscles of Pecten maximus following the procedure described by Gäde and Carlsson (1984). Inorganic phosphate $\left(\mathrm{P}_{\mathrm{i}}\right)$ concentrations were measured enzymatically according to Pörtner (1990).

\section{Chemicals}

All chemicals were purchased from Sigma Chemicals (St. Louis, Mo., USA) or Merck (Darmstadt, Germany).

\section{Derived indices}

Adenylate energy charge (AEC) was calculated using the traditional formula:

$$
\mathrm{AEC}=\frac{[\mathrm{ATP}]+0.5 \times[\mathrm{ADP}]}{[\mathrm{ATP}]+[\mathrm{ADP}]+[\mathrm{AMP}]}
$$

where $[\mathrm{AMP}],[\mathrm{ADP}]$ and $[\mathrm{ATP}]$ are concentrations $\left(\mu \mathrm{mol} \mathrm{g}{ }^{-1}\right.$ wet weight) of the corresponding compounds.

The relative amount of phosphagen $\left(R_{P L A}\right)$ was calculated according to the formula:

$\mathrm{R}_{\mathrm{PLA}}=\frac{[\mathrm{PLA}]}{[\mathrm{PLA}]+[\mathrm{Arg}]}$

where [PLA] and [Arg] are tissue concentrations of PLA and Arg, respectively ( $\mu \mathrm{mol} \mathrm{g}^{-1}$ wet weight). 
The rate of ATP turnover during anaerobiosis (amount of ATP consumed per gram wet weight per day) was calculated from endproduct accumulation and ATP and PLA depletion as described in Pörtner et al. (1984). An ATP equivalent of $2.75 \mu \mathrm{mol} \mu \mathrm{mol}^{-1}$ succinate was adopted (de Zwaan 1983). The aerobic ATP turnover rate was calculated from routine oxygen consumption rates assuming ATP production of $6 \mathrm{~mol} \mathrm{ATP} \mathrm{mol}^{-1} \mathrm{O}_{2}$.

The Gibbs free energy change $(\mathrm{dG} / \mathrm{d} \xi)$ of ATP hydrolysis was calculated according to the methodology described in detail by Pörtner et al. (1996). Concentrations of ATP, PLA, Arg and $P_{i}$ were adopted from this study, whereas $\mathrm{pH}_{\mathrm{i}}$ and concentrations of free magnesium ions were calculated from ${ }^{31} \mathrm{P}-\mathrm{NMR}$ spectra as described in our companion paper (Sokolova et al. 1999).

Statistics

Statistical treatment was performed using standard Model I ANOVA after testing the assumptions of normal distribution and homogeneity of variance of the data (Sokal and Rohlf 1995). We used Tukey's honestly significant difference (HSD) test for unequal $n$ as a method of post-hoc comparisons. Parameters of linear regression were calculated according to Sokal and Rohlf (1995), and the fitting of the data into the linear regression model was estimated by ANOVA. Pairwise comparison of slope and intercept of regression lines was performed after algorithm described in Urbakh (1964). The differences were considered significant if the probability level of Type I error was less than 0.05. Results are expressed as percentages or mean values \pm SE.

Prior to statistical analysis, respiration rates (calculated as $\mu \mathrm{g} \mathrm{O}_{2}$ consumed per hour per gram wet tissue weight) were standardised to the average wet tissue weight in each experimental group ( $L$. saxatilis, L. obtusata or L. littorea) according to formula 3:

$\mathrm{R}_{\mathrm{st}}=\mathrm{R}_{\mathrm{i}} \times\left(\frac{\overline{\mathrm{W}}}{\mathrm{W}_{\mathrm{i}}}\right)^{\mathrm{b}}$

where $R_{\text {st }}$ is a standardised respiration rate $\left(\mu g \mathrm{O}_{2} \mathrm{~h}^{-1} \mathrm{~g}^{-1}\right), \mathrm{R}_{\mathrm{i}}$ is a respiration rate of $\mathrm{i}$-th animal $\left(\mu \mathrm{g} \mathrm{O} \mathrm{O}_{2} \mathrm{~h}^{-1} \mathrm{~g}^{-1}\right), \mathrm{W}_{\mathrm{i}}$ is wet tissue weight of $\mathrm{i}$-th animal $(\mathrm{g}), \bar{W}$ is the average wet tissue weight in the experimental group $(\mathrm{g})$, and $\mathrm{b}$ is a power coefficient in equation: $\mathrm{R}=\mathrm{aW}$. This coefficient was obtained by a calculation of the linear regression relating $\log \mathrm{W}$ to $\log \mathrm{R}$ by the least square method (Sokal and Rohlf 1995).

\section{Results}

\section{Respiration rates under control conditions}

Standardised aquatic respiration rates were similar in the three studied species and equalled $81.0 \pm 3.8 \mu \mathrm{g}$ $\mathrm{O}_{2} \mathrm{~h}^{-1} \mathrm{~g}^{-1}, \quad 76.6 \pm 3.3 \mu \mathrm{g} \mathrm{O}_{2} \mathrm{~h}^{-1} \mathrm{~g}^{-1}$ and $67.1 \pm$ $2.2 \mu \mathrm{g} \mathrm{O}_{2} \mathrm{~h}^{-1} \mathrm{~g}^{-1}$ in L. obtusata, L. littorea and L. saxatilis, respectively. Tukey's HSD test showed that the respiration rate was significantly higher in L. obtusata as compared to L. saxatilis $(P<0.01)$.

The allometric relationship between soft body weight and respiration rate was statistically significant for L. saxatilis $(b=-0.378, P<0.05)$ and $L$. littorea ( $b=-0.826, \quad P<0.01)$, but not for $L$. obtusata $(b=0.068, P>0.80)$. However, our data do not suggest an allometric dependency of aerobic metabolism on body size in a between-species comparison, as two species with similar body size (L. saxatilis and L. obtusata) had the most contrasting respiration rates, and the largest one, L. littorea, demonstrated an intermediate rate of oxygen consumption.
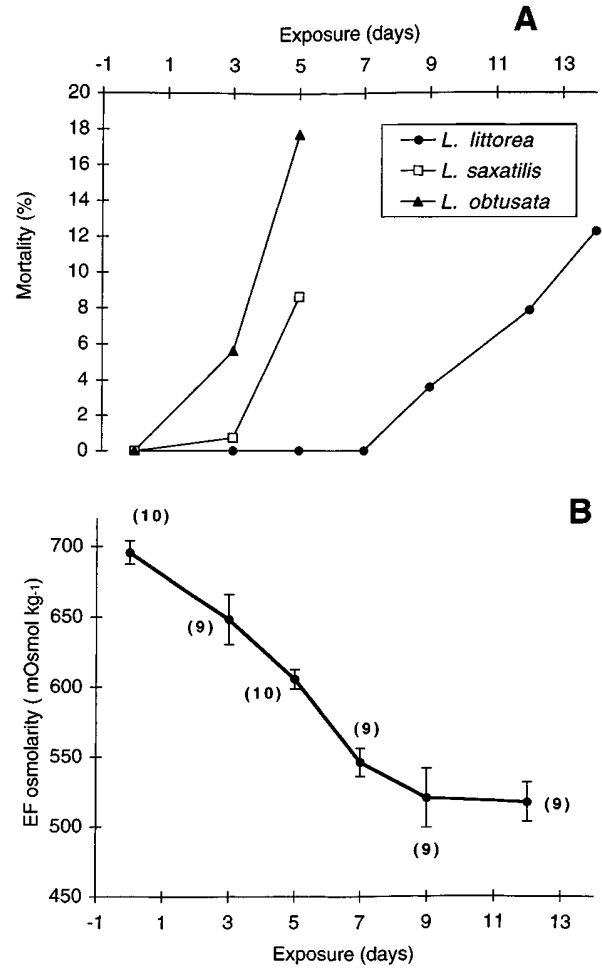

Fig. 1 Mortality of White Sea periwinkles (A) and changes in the osmotic concentration of extravisceral fluid of Littorina littorea (B) during freshwater exposure. A The number of snails scored for mortality varied between $20-90$ in L. littorea and $500-1000$ in the other two species. B Vertical bars represent SE of the mean, $n$ is given in brackets. Note the fairly stable osmolarity of extravisceral fluid (EF) between days 7 and 12 despite increasing mortality in L. littorea

\section{Mortality rates and osmotic concentration of EF}

Mortality during freshwater exposure was different in the three studied species. L. littorea was the most resistant species and L. obtusata the least resistant one (Fig. 1A). Onset of mortality occurred between the 7 th and 9th day of freshwater exposure in L. littorea, at the 3 rd day of exposure in L. saxatilis, and apparently before the 3rd day of exposure in L. obtusata.

Owing to the limited size of the other species, the osmotic concentration of the EF was measured only in L. littorea. During freshwater exposure, the osmolarity of EF was significantly reduced $(P<0.05)$ from 696 mOsmol kg-1 $(26.7 \%)$ to $517 \mathrm{mOsmol} \mathrm{kg}^{-1}(19.8 \%$ oo $)$ and levelled at approximately $20 \%$ during days $7-12$ of the experiment (Fig. 1B).

Accumulation of anaerobic end products

The mean concentration of succinate in the foot tissue did not differ significantly between control animals of either species and ranged between $0.2 \mu \mathrm{mol} \mathrm{g}^{-1}$ and $0.8 \mu \mathrm{mol} \mathrm{g}{ }^{-1}$ wet weight. During freshwater exposure, snails showed marked accumulation of this end product (Fig. 2), and tissue succinate levels of the experimental 


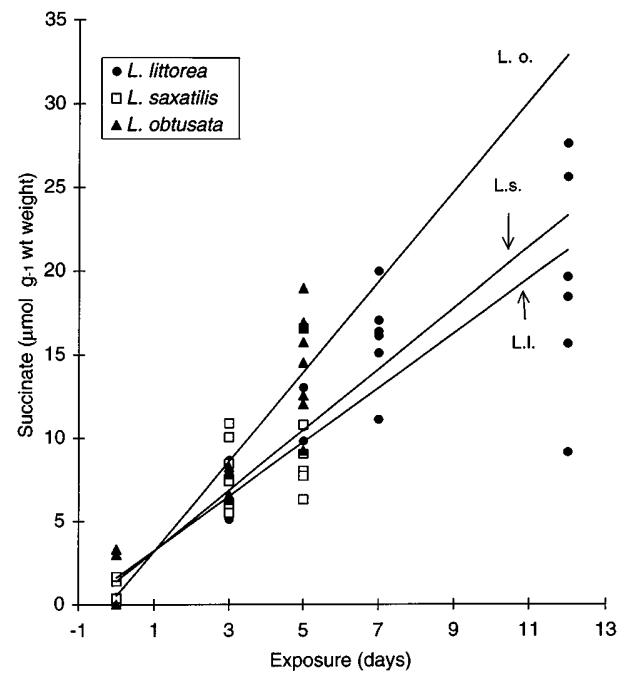

Fig. 2 Succinate accumulation in foot tissues of three species of White Sea periwinkles during freshwater exposure. Dots represent original data, and lines are linear regressions for succinate accumulation over time in Littorina littorea (L.l) $(\mathrm{Suc}=1.37+1.65 *$ Exp), Littorina saxatilis (L.s.) $\quad$ Suc $=1.39+1.82 *$ Exp) and Littorina obtusata $($ L.o $)(\mathrm{Suc}=0.08+2.79 * \mathrm{Exp})$ where Suc is succinate concentration ( $\mu \mathrm{mol} \mathrm{g}^{-1}$ wet weight) and Exp is exposure duration (days). All regressions are statistically significant $(P<0.05)$

animals were significantly above control values in all studied species. The rate of increase in succinate concentration was adequately approximated by the linear regression model (Fig. 2). Intercepts did not differ from zero in either studied species. Pairwise between-species comparisons suggested that rates of succinate accumulation (= slopes of the regression lines) were similar in L. littorea and $L$. saxatilis $(P>0.05)$, but significantly higher in L. obtusata $(P<0.05)$ during $0-5$ days of freshwater exposure.

Besides succinate, we tested for the following end products of anaerobic metabolism: opines (alanopine and strombine), lactate (D- and L-stereoisomeres not being separated), acetate and propionate. None of these metabolites were present in control animals nor accumulated during the experiment in amounts detectable by the methods applied.

High-energy phosphates and energy status of the tissue

\section{Phosphagen}

Mean values of PLA or Arg contents, as well as the $R_{P L A}$ ratio did not differ significantly in control animals of either studied Littorina spp. During exposure to fresh water, the amount of PLA declined significantly in all studied species as compared to the respective control values (Fig. 3A). It is worth noting that the phosphagen was nearly depleted already after 3 days of freshwater exposure. After that time no further decline in PLA content was detected in either studied species (Fig. 3A).
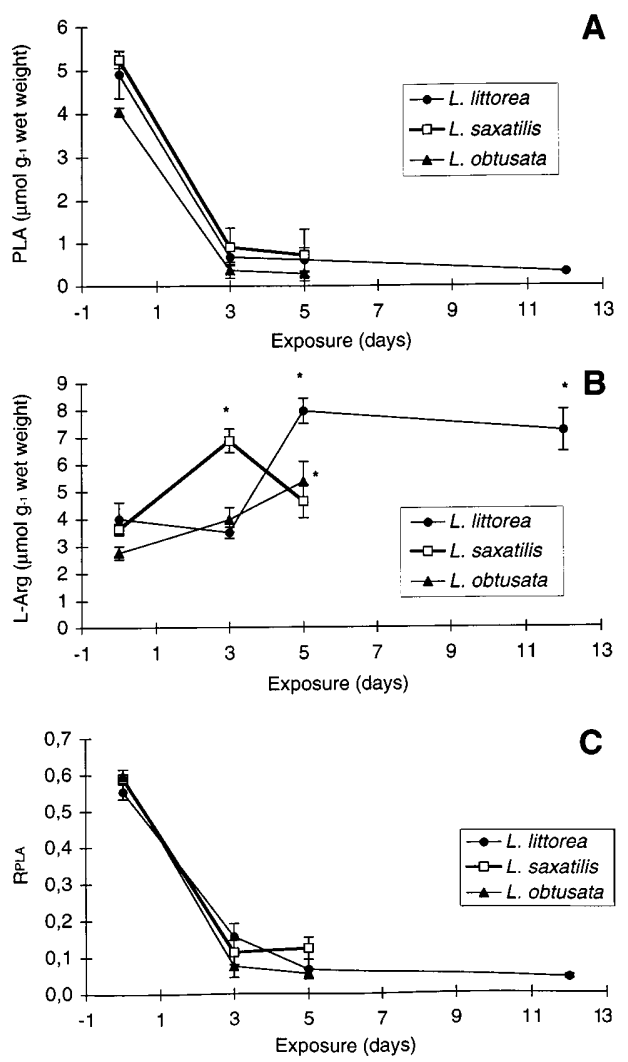

Fig. 3 Changes in the concentrations of phospho-L-arginine (PLA; A) and L-arginine (Arg; B) and relative amount of phospho-L-arginine, $\mathrm{R}_{\text {PLA }}(\mathbf{C})$ in White Sea Littorina spp. during freshwater exposure. Vertical bars represent standard errors; $n$ is $4-5$. A, $\mathbf{C}$ - all values for days 3-12 of exposure are significantly different from the respective controls; B - values which are significantly different from the respective controls are marked with asterisks. The irregular pattern of the changes in Arg content is probably due to the catabolism and or unregistered efflux of this metabolite

The concentrations of PLA were similar in the studied Littorina spp. for all comparable exposure periods $(P>0.60)$. Phosphagen depletion was accompanied by the concomitant increase in Arg content (Fig. 3B). However, the pattern of change in the concentrations of this metabolite was not as clear as for PLA.

The relative amount of phosphagen in the total phosphagen/aphosphagen pool $\left(\mathrm{R}_{\mathrm{PLA}}\right)$ decreased significantly during freshwater exposure. The rate of decline was fastest in the least resistant species, L. obtusata, and somewhat slower in L. littorea and L. saxatilis (Fig. 3C). However, due to the high inter-individual variability of this ratio, no statistically significant differences were found between the studied species at either of the comparable exposure periods.

\section{Adenylates}

In control animals, no significant differences were found between the studied species in the levels of different adenylate compounds or the total concentration of adenylates. 

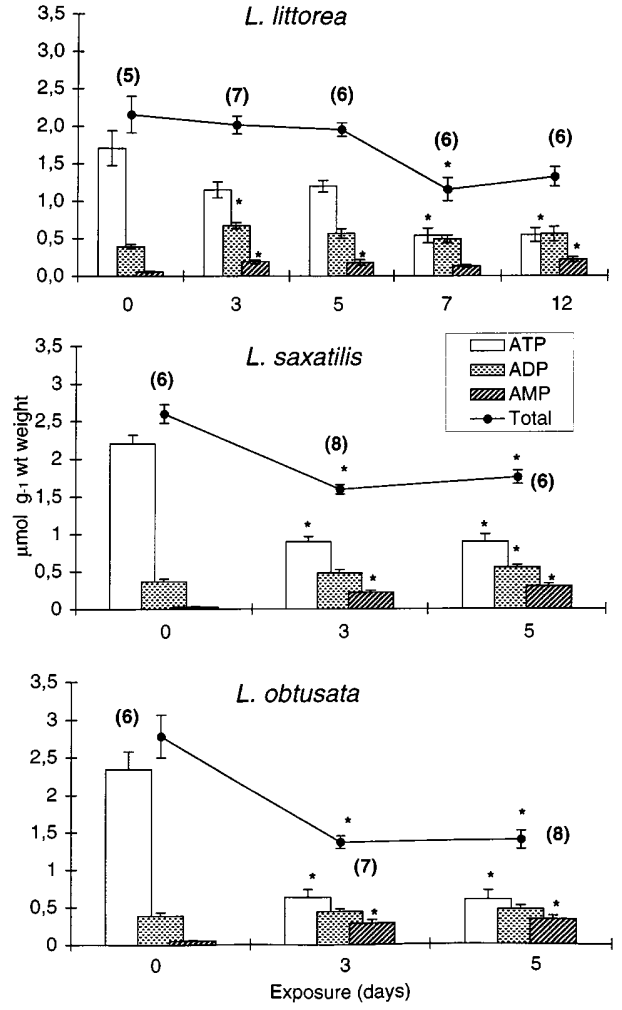

Fig. 4 Concentrations of adenine nucleotides in the foot tissues of White Sea Littorina spp. during freshwater exposure. The total concentration of adenylates is shown by closed circles connected with a solid line. Vertical bars represent SE. The number of samples examined for each exposure period is given in brackets. Values which are significantly different from the respective control concentrations are marked with an asterisk

In all studied Littorina spp., the amount of AMP in the foot muscle increased during freshwater exposure (Fig. 4). However, the rates of AMP accumulation were different. The rate of increase in AMP content was slowest in L. littorea. In this species, the average AMP concentration equalled $0.18 \mu \mathrm{mol} \mathrm{g}^{-1}$ wet weight at day 5 of freshwater exposure, whereas the respective values in L. saxatilis and L. obtusata were $0.31 \mu \mathrm{mol} \mathrm{g}^{-1}$ and $0.33 \mu \mathrm{mol} \mathrm{g}^{-1}$ wet weight, respectively. The AMP content in L. littorea muscles reached only $0.22 \mu \mathrm{mol} \mathrm{g} \mathrm{g}^{-1}$ wet weight at the end of the experiment which lasted for 12 days.

ADP concentrations increased during freshwater exposure in $L$. littorea and $L$. saxatilis, but remained fairly constant in L. obtusata (Fig. 4). In contrast, the concentration of ATP showed a significant decline during freshwater exposure in all three species. The decrease in the ATP content was fastest in L. obtusata, intermediate in L. saxatilis and slowest in L. littorea. After 5 days of freshwater exposure, the mean relative amount of ATP equalled $0.47,0.68$ and $0.81 \mu \mathrm{mol} \mathrm{g}^{-1}$ wet weight in L. obtusata, L. saxatilis and L. littorea, respectively (Fig. 4). It is worth noting that ATP concentration dropped significantly below control levels after 3 days of exposure in $L$. saxatilis and L. obtusata, and only after 7 days in L. littorea.
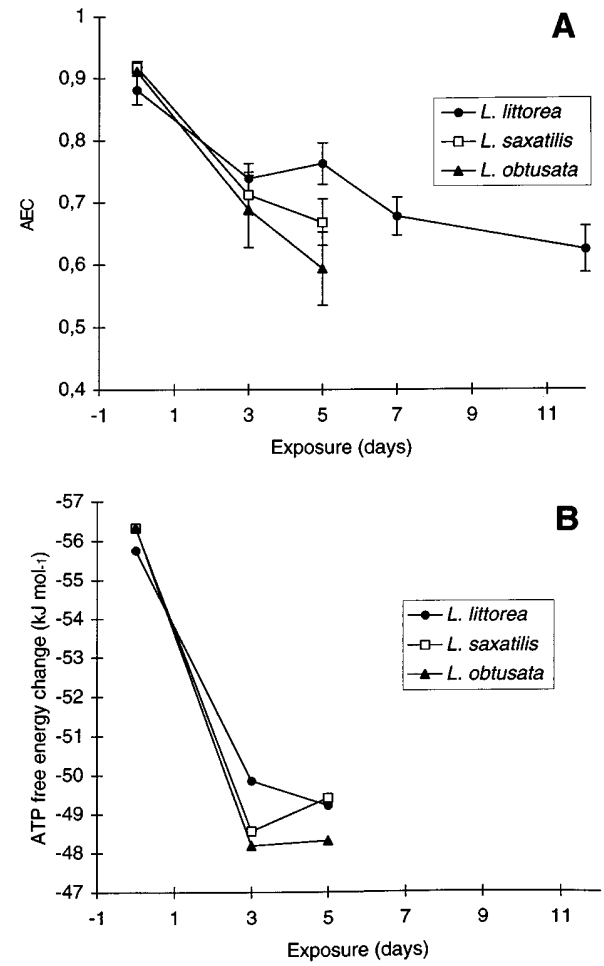

Fig. 5 Adenylate energy charge (AEC; A) and Gibbs free energy (B) of ATP hydrolysis in White Sea Littorina spp. during freshwater exposure. A Vertical bars represent SE. Number of samples for each exposure period is the same as in Fig. 4. AEC values after 3-12 days of exposure are significantly different from the respective controls in either of the studied species. B The Gibbs free energy change of ATP hydrolysis was calculated using average values of intracellular parameters (ATP, PLA, $\mathrm{P}_{\mathrm{i}}, \mathrm{pH}_{\mathrm{i}}$, etc.) for each exposure period. Note a good correspondence between the pattern of changes in AEC and ATP free energy change during the first 5 days of freshwater exposure

The total amount of adenylates in the muscle tissue also decreased during the experiment. Again, the rate of this decline differed between the studied species. After 5 days of freshwater exposure, adenylates decreased by $0.53 \mu \mathrm{mol} \mathrm{g}^{-1}$ and $0.94 \mu \mathrm{mol} \mathrm{g}^{-1}$ wet weight below control levels in L. saxatilis and L. obtusata, respectively. In L. littorea, no significant change in the adenylates concentration of the foot muscle was observed until after day 7 of experimentation. At this point, the adenylate content declined significantly by $0.63-0.80$ $\mu \mathrm{mol} \mathrm{g}{ }^{-1}$ wet weight.

The AEC in the muscle tissues of control animals was very similar at $0.85-0.90$. During freshwater exposure a marked decrease of AEC was found (Fig. 5A). After 3 days of exposure this decline was equally pronounced in all studied species, but at day 5 the AEC of L. littorea foot tissue was significantly higher than in L. obtusata. At this time the AEC of L. saxatilis tissues did not differ significantly from either species.

The dynamics of the free energy change of ATP hydrolysis followed a similar trend. Under control conditions, $\mathrm{dG} / \mathrm{d} \xi$ values were very similar in the three studied species and varied between $-55.7 \mathrm{~kJ} \mathrm{~mol}^{-1}$ and $-56.3 \mathrm{~kJ}$ $\mathrm{mol}^{-1}$ (Fig. 5B). In freshwater-exposed Littorina spp. a 


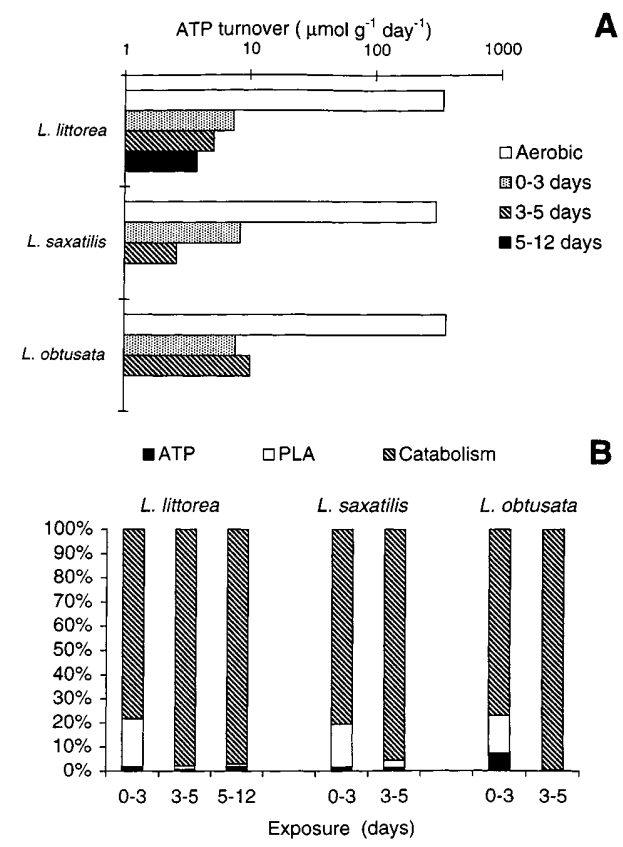

Fig. 6A, B ATP turnover rates $\left(\dot{M}_{\mathrm{ATP}}\right)$ in White Sea Littorina spp. during freshwater exposure. A Aerobic ATP turnover was calculated from the routine oxygen consumption rates of Littorina spp. assuming formation of $6 \mathrm{~mol}$ ATP per mol of consumed $\mathrm{O}_{2}$. Anaerobic $\dot{M}_{\text {ATP }}$ was calculated from the change in succinate concentration assuming production of $2.75 \mu \mathrm{mol} \mathrm{ATP} \mathrm{m^{-1 }}$ of accumulated succinate, as well as from ATP and phosphagen depletion over the respective exposure periods. B Relative amount of ATP equivalents derived from different sources during freshwater exposure in White Sea Littorina spp

"drop" (meaning a decrease in driving force) of the Gibbs free energy of ATP hydrolysis was observed to between $-48.1 \mathrm{~kJ} \mathrm{~mol}^{-1}$ and $-49.2 \mathrm{~kJ} \mathrm{~mol}^{-1}$. It was most pronounced and occurred somewhat faster in the least resistant species, L. obtusata, whereas the least and a slower decrease in the driving force of ATPases was found in the most resistant $L$. littorea. However, values of $\mathrm{dG} / \mathrm{d} \xi$ were quite close in the three studied species throughout the exposure periods, the between-species variation comprising less than $2 \mathrm{~kJ} \mathrm{~mol}^{-1}$.

The comparison of aerobic and anaerobic ATP turnover rates $\left(\dot{M}_{\mathrm{ATP}}\right)$ suggests the onset of a dramatic metabolic rate depression in all three species during freshwater exposure. During the first 3 days of freshwater exposure, $\dot{M}_{\text {ATP }}$ varied between $7.3 \mu \mathrm{mol} \mathrm{\textrm {g } ^ { - 1 }}$ day $^{-1}$ and $8.3 \mu \mathrm{mol} \mathrm{g}{ }^{-1}$ day $^{-1}$ which is equivalent to $2-$ $3 \%$ of the aerobic $\dot{M}_{\text {ATP }}$ of the studied species (Fig. 6A). Subsequently, $\dot{M}_{\text {ATP }}$ during freshwater exposure decreased considerably in L. saxatilis and L. littorea (to down to $1-1.5 \%$ of aerobic $\dot{M}_{\text {ATP }}$ ), but not in L. obtusata (Fig. 6A).

The relative amount of ATP equivalents derived from different sources was similar in the studied species and changed considerably in the course of freshwater exposure (Fig. 6B). During the first 3 days of exposure, 5.5$1.2 \%$ of total ATP turnover was due to the breakdown of ATP stored in the tissue. Utilisation of phosphagen comprised $16-20 \%$ of the ATP turnover. Most ATP equivalents at this time derived from succinate production (78.5-78.7\%). Later on, the relative amount of ATP equivalents derived from the utilisation of ATP and phosphagen stores greatly reduced to $<0.01-0.5 \%$ (for ATP) and $0.1-3.1 \%$ (for phosphagen). The vast majority of ATP equivalents (96.9-99.7\%) were derived from catabolism.

It is worth noting that in our study we used a standard method of PCA extraction that is widely applied for different animal tissues (Bergmeyer 1985). However, as was pointed out by one of the reviewers of this paper, tissue adenylate levels may be underestimated by this approach in calcium-rich molluscan tissues due to the artifactual precipitation of adenylates. To test for this effect, we performed an additional series of experiments in L. littorea and carried out tissue extractions with PCA containing EDTA in order to trap the $\mathrm{Ca}^{2+}$ ions. It was found that addition of EDTA significantly influenced the measurable amount of ATP (ANOVA: $\left.F_{1,20}=194.00, P<0.0001\right)$, whereas ADP or AMP levels were not significantly affected (ANOVA: $F_{1,20}=0.15, P=0.70$ and $F_{1,20}=1.04, P=0.32$ for ADP and AMP, respectively). Addition of EDTA increased ATP levels by $20-25 \%$ in the tissues of the control and freshwater-exposed animals. ATP concentration in the tissue samples extracted with EDTA was higher by a factor of $1.32 \pm 0.09(n=4)$ in controls and by a factor of $1.25 \pm 0.11(n=8)$ after 3 days of freshwater exposure. These factors were not significantly different in control and freshwater-exposed animals (ANOVA: $F_{1,10}=0.172, P=0.69$ ) indicating that the increase in ATP levels was proportional in these groups, despite the drastic difference in ATP levels (see below). This effect should be the same in all three studied Littorina species, because of similar calcium levels found in the tissue homogenates of these species (Sokolova et al. 1999). Hence, the correction for potential calcium precipitation of ATP would have no effect on the between-species comparisons of the dynamics of these parameters during freshwater exposure or on the $\mathrm{dG} / \mathrm{d} \xi$ of ATP hydrolysis. Nonetheless, we corrected ATP, adenylate and AEC levels in Figs. 4-6 indusive for this effect. As expected, this correction did neither change the overall picture of dynamics of adenylate concentrations and energy related parameters, nor the statistical significance of the above-described contrasts (data not shown).

\section{Inorganic phosphate}

Changes in $\mathrm{P}_{\mathrm{i}}$ concentration during freshwater exposure showed variable patterns among studied species (Table 1). In L. littorea, changes in $\mathrm{P}_{\mathrm{i}}$ content between control and freshwater-exposed animals were not statistically significant. In contrast, a significant increase of $\mathrm{P}_{\mathrm{i}}$ concentration was found in L. saxatilis and L. obtusata after 3 or 5 days of freshwater exposure as compared to the respective control levels. 
Table 1 Concentration of inorganic phosphate $\left(\mu \mathrm{mol} \mathrm{g}{ }^{-1}\right.$ wet weight) in the foot tissues of White Sea periwinkles during freshwater exposure

\begin{tabular}{lllllll}
\hline Exposure & Littorina littorea & $n$ & Littorina saxatilis & $n$ & Littornia obtusata & $n$ \\
\hline 0 & $2.64 \pm 0.54$ & 6 & $1.90 \pm 0.36$ & 5 & $2.22 \pm 0.15$ & 5 \\
3 & $4.33 \pm 0.85$ & 6 & $4.12 \pm 0.72^{*}$ & 4 & $4.09 \pm 0.49^{*}$ & 7 \\
5 & $3.09 \pm 0.70$ & 5 & $3.75 \pm 0.40^{*}$ & 6 & $2.85 \pm 0.62$ & 6 \\
12 & $2.11 \pm 0.87$ & 4 & - & - & - & - \\
\hline
\end{tabular}

* indicates values that are significantly different from the respective control $(P<0.05)$

\section{Discussion}

Freshwater resistance and osmotic changes of the internal medium

Exposure to long periods of extremely low salinity is not an unrealistic experience for White Sea Littorina spp. Marked seasonal salinity variations are a well known feature of the White Sea (Kuznetsov 1960). In open parts of the studied area of Kandalaksha Bay, surface water salinity can drop down to $2 \%$ for as long as a fortnight during spring ice-melting (Babkov and Lukanin 1985). This salinity is well below levels tolerated by the periwinkles and causes behavioural escape response (isolation). In estuaries such periods of low salinity may be even longer and more pronounced (Berger 1986). The three studied species of periwinkles demonstrated different levels of resistance to freshwater exposure. Survival rates in fresh water decrease in the order L. littorea $<$ L. saxatilis $<L$. obtusata. Similar results were previously reported by Berger (1986). During freshwater exposure a significant dilution of the EF was observed in $L$. littorea. However, the rate of salt and water exchange between the EF and ambient water is rather slow, so that after 12 days of freshwater exposure the osmolarity of the EF was only reduced by $26 \%(7 \%)$. The mortality onset was detected between the 7th and 9th day of exposure, when the EF osmotic concentration of survivors was $521-546 \mathrm{mmol} \mathrm{kg}^{-1}$ (about $20 \%$ ). This salinity is easily tolerated by the White Sea Littorina spp. with normal activity maintained and no mortality detected under these conditions (Berger 1986; Sokolova, personal observation). Similarly, during freshwater incubation of White Sea L. saxatilis, the freezing point depression of the EF was $-0.65 \pm 0.03{ }^{\circ} \mathrm{C}$ at the time of mortality onset (Berger 1980) which is roughly equivalent to $11 \%$. This salinity could also be tolerated by the White Sea L. saxatilis without any drastic consequences for survival (Sokolova, personal observation). Thus, the osmotic shock does not seem to be a primary reason for the mortality of periwinkles during freshwater exposure.

Anaerobic metabolism during fresh water exposure: end product accumulation and metabolic arrest

Important factors potentially determining limits for survival of animals during prolonged anoxia are the depletion of high-energy phosphate and substrate stores and/or metabolic acidification of the tissues. We followed the time courses of anaerobic product accumulation and changes in parameters of energy status of the snails and compared these to the mortality rates of the three Littorina spp. in order to find out which is the crucial parameter for survival under conditions of freshwater exposure. Presumably, the limiting parameter should reach the same value in all species at the time of the onset of mortality.

Our study has for the first time clearly demonstrated that freshwater exposure leads to the onset of anaerobiosis in these marine gastropods. Onset of anaerobic energy metabolism in freshwater-exposed periwinkles is clearly indicated by significant succinate accumulation. This metabolite is regarded as an ideal signal of anaerobiosis within the mitochondrial compartment of the cells (Grieshaber et al. 1994). The rate of succinate accumulation which is indicative of anaerobic metabolic rate, is the highest in the least resistant species, L. obtusata, and fairly similar in the other two species with intermediate and high freshwater resistance. Mortality sets in irrespective of the maximum level of succinate reached, so there seems to be no specific tolerance limit to succinate acumulation in Littorina spp.

The succinate concentration detected in the White Sea periwinkles is much higher than the levels ever reported for the conspecifics from other parts of the distributional range. The net accumulation of succinate in the foot muscle of the North Atlantic L. littorea after $24 \mathrm{~h}$ of anoxia exposure at $12{ }^{\circ} \mathrm{C}$ was only $1.4 \mu \mathrm{mol} \mathrm{g}$ wet weight (Storey et al. 1982). No increase in succinate content was found in these animals after $24 \mathrm{~h}$ or $72 \mathrm{~h}$ of anoxia at $5{ }^{\circ} \mathrm{C}$ (Churchill and Storey 1996). Similarly, in two other marine gastropod species (Patella caerulea and Bysycotypus canaliculatum) succinate levels after $12-16 \mathrm{~h}$ of anoxia exposure did not exceed $0.4 \mu \mathrm{mol} \mathrm{g}{ }^{-1}$ and $2 \mu \mathrm{mol} \mathrm{g}^{-1}$ wet weight, respectively (Michaelidis and Beis 1990; Storey et al. 1990). Even smaller was the accumulation of this metabolite in the foot muscle of the subtidal snail Hexaplex trunculus (Xomali et al. 1996). In contrast, the whole body succinate content in the brackish water intertidal gastropod Onchidium tumidium rose up to ca. $14 \mu \mathrm{mol} \mathrm{g}^{-1}$ wet weight after $48 \mathrm{~h}$ of anoxia at $25{ }^{\circ} \mathrm{C}$ (Lim et al. 1996) which is comparable to the values found in White Sea periwinkles. However, due to different experimental temperatures and general experimental design (in particular, the duration of exposure to fresh water/anoxia stress), it is difficult to make direct comparisons of succinate accumulation in White Sea Littorina spp. and other gastropods so far studied in this respect. The different succinate levels 
reached in North Atlantic and White Sea L. littorea are similar to the substantial differences in succinate accumulation observed in North Sea and White Sea Arenicola marina. Higher succinate accumulation in subpolar animals is most likely related to the higher mitochondrial density in cold-adapted subpolar invertebrates (Sommer et al. 1997).

Surprisingly, succinate was the only tested end product which accumulated in detectable amounts in the White Sea Littorina spp. during anoxic incubation. Contents of alanopine, strombine, lactate, acetate or propionate were below detection limits in control and experimental animals. These results contradict the finding of previous researchers. Opine and lactate dehydrogenase activities were reported for foot muscle of L. littorea and L. obtusata (=Littorina littoralis) from North Atlantic and Pacific coasts by various authors (Hammen 1969; Livingstone et al. 1983; Kreutzer et al. 1989; Hammen and Bullock 1991). In L. littorea and L. obtusata from these areas, significant accumulation of alanopine, strombine and/or D-lactate was observed during environmental hypoxia (Grieshaber and Kreutzer 1987; Kreutzer et al. 1989; Churchill and Storey 1996), whereas octopine and L-lactate concentrations were below detection limits (Kreutzer et al. 1989).

Investigations of opine accumulation during anoxia in various marine invertebrates suggested that the production and relative amount of the specific opine is strongly dependent on the concentration of the amino acid used in the reductive condensation with pyruvate (Grieshaber and Kreutzer 1987; Kreutzer et al. 1989). Possibly, the absence of opine accumulation in anoxic Littorina may be explained by the lower intracellular levels of free amino acids in White Sea periwinkles owing to the lower salinity in this region $(25-27 \%$ in the surface layer in summer, Kuznetsov 1960) as compared to North Atlantic sites with full salinity. However, this suggestion does not account for the absence of lactate accumulation which is produced directly from pyruvate without involving an amino acid.

More likely, the high succinate levels might explain the absence of lactate and opine accumulation in White Sea periwinkles during freshwater exposure. Anaerobic glycolysis in the cytosol may be reduced in facultative anaerobes with high levels of mitochondria which may go hand in hand with a higher capacity of succinate fermentation. In these animals opines may only be formed in functional anaerobiosis or post-anaerobic recovery processes (Livingstone 1991) and no longer during the transition to environmental anaerobiosis (Pörtner 1993). This may be related to a larger flexibility of mitochondrial metabolism in cold-adapted invertebrates.

However, these considerations do not explain the absence of volatile fatty acids (acetate and propionate) which are also produced in the mitochondrial compartment of the cell (Pörtner 1993). Release from the tissue into EF or ambient water is unlikely because in many marine invertebrates which are known to produce volatile fatty acids during environmental anaerobiosis (e.g. the lugworm Arenicola marina, the peanut worm Sipunculus nudus, and the mussel Mytilus galloprovincialis), considerable amounts of these metabolites are retained by tissues despite high excretion rates (Grieshaber et al. 1994; Isani et al. 1995; Sommer et al. 1997). Furthermore, excretion should be even less pronounced in freshwater-exposed periwinkles due to reduced rate of exchange between tissues and EF, on one side, and ambient water, on the other (Rumsey 1973; Berger 1986; this study). Obviously, acetate/propionateproducing pathways are not involved in anaerobic energy production of White Sea Littorina spp. during long-term freshwater exposure.

Resistance to long-term anoxia in facultative anaerobes usually implies a strategy of metabolic rate depression or metabolic arrest (de Zwaan and van den Thillart 1985; Storey and Storey 1990; Livingstone 1991; Grieshaber et al. 1994). Efficient metabolic arrest requires the coordinated downregulation of both energy production and energy consumption. It prevents the fast and extreme depletion of cellular energy stores and increases the time span of the organism's survival under conditions of environmental stress. Our data provide clear evidence that environmental anaerobiosis caused by freshwater exposure induces the onset of very efficient metabolic arrest in all three studied Littorina spp. Anaerobic rates of ATP turnover comprised not more than $3 \%$ of the aerobic rate. Detailed comparisons suggest that the efficiency of metabolic rate depression differs between the three studied species and correlates with their differential freshwater resistance. Although $\dot{M}_{\mathrm{ATP}}$ was similar in all three Littorina spp. during the initial phase of freshwater exposure, the two more resistant species (L. littorea and L. saxatilis) later on demonstrated considerable further decrease in $\dot{M}_{\text {ATP }}$, whereas the most susceptible, L. obtusata, was unable of additional metabolic arrest. The rate of ATP turnover of this species even increased during prolonged exposure.

\section{Impact of anaerobiosis on tissue energy status}

The control concentrations of PLA, which is the only phosphagen known in molluscan tissues (Grieshaber et al. 1994), averaged $4-5 \mu \mathrm{mol} \mathrm{g}{ }^{-1}$ wet weight in the foot muscles of the White Sea Littorina spp. These values are two to three times lower than those reported for other marine gastropods (for review, see Grieshaber et al. 1994) possibly reflecting lower capacities of phosphagen utilisation in mitochondria-rich tissues. During freshwater exposure, a fast and marked breakdown of the phosphagen was observed in the periwinkles. PLA was nearly depleted already after 3 days of freshwater exposure. No significant correlations were observed between the rate and/or extent of phosphagen depletion and the freshwater resistance of the studied species. The observed pattern of changes in phosphagen concentration corresponds to the generally accepted role of 
phosphagen as a source for fast energy provision during functional anaerobiosis and early transitional stage of environmental anaerobiosis (Grieshaber et al. 1994). During later stages of anaerobiosis the phosphagen pool remains exhausted and is not involved in ATP production. Replenishment occurs upon aerobic recovery (Kamp 1993; van den Thillart and van Waarde 1996). Accordingly, phosphagen breakdown contributed ca. $16-20 \%$ of ATP production during the initial period of freshwater exposure and was equivalent to $0.1-3 \%$ for the whole exposure period in the studied Littorina spp. Hence, differences in phosphagen pool and/or rates of phosphagen utilisation should have negligible influence on the ability to survive freshwater exposure in the periwinkles.

The total amount of adenylates found in control White Sea littorines ranged between $1.8 \mu \mathrm{mol} \mathrm{g}^{-1}$ and $2.2 \mu \mathrm{mol} \mathrm{g}^{-1}$ wet weight. These values are slightly higher than those reported for $L$. littorea by Churchill and Storey (1996) $\left(1.47 \mu \mathrm{mol} \mathrm{g}^{-1}\right.$ wet weight). Concentrations of different adenine nucleotides decreased in the order ATP $>$ ADP $>$ AMP which is typical for unstressed animals (Beis and Newsholme 1975). During freshwater exposure ATP levels declined significantly in all studied species, however, at different rates. ATP breakdown was fastest in the least resistant L. obtusata and slowest in the most resistant species, L. littorea. Decrease in ATP content was linked to a parallel increase in ADP and especially AMP concentrations, however, the rise in ADP levels was not always significant. Total adenylate content declined during freshwater exposure in the three studied Littorina spp. which was probably a result of AMP degradation (Atkinson 1977; Pörtner 1987a).

Despite significant net breakdown of phosphagen and ATP, enzymatically determined inorganic phosphate showed only a slight (if any) increase during freshwater exposure. This is an unexpected finding because phosphagen and ATP depletion are assumed to lead to a stoichiometric increase in free $\mathrm{P}_{\mathrm{i}}$ levels (Pörtner 1987b and references therein). Moreover, studies of functional anaerobiosis during increased exercise in the squid Illex illecebrosus and Lolliguncula brevis showed that accumulated $\mathrm{P}_{\mathrm{i}}$ does not leave the muscle cells during rather short term stress (Pörtner et al. 1996). Long term release from the cells appears possible (Pörtner et al. 1991). Alternatively, there might have been a measurement artefact owing to $P_{i}$ precipitation by $\mathrm{Ca}^{2+}$ derived from the calcium carbonate stores of the foot muscle (Mason et al. 1984; see also Sokolova et al. 1999).

The decrease in high-energy phosphate concentrations during prolonged freshwater exposure led to an impaired energy status of the tissues in White Sea Littorina spp. reflected in a decline of the adenylate energy charge and the free energy change of ATP hydrolysis. The driving force by ATP hydrolysis (absolute value of the $\mathrm{dG} / \mathrm{d} \xi$ ) decreased from ca. $56 \mathrm{~kJ} \mathrm{~mol}^{-1}$ under control conditions to a minimum of $48-49 \mathrm{~kJ} \mathrm{~mol}^{-1}$ after 35 days of freshwater exposure. Although our data give only a rough estimate of the species-specific differences in the free Gibbs energy of ATP hydrolysis and allow no statistical comparison, they suggest that prolonged freshwater exposure may probably have a larger impact on the energy status of the least resistant species $L$. obtusata in which the drop of $\mathrm{dG} / \mathrm{d} \xi$ was largest among the three species. This suggestion is also supported by a significantly faster and more pronounced drop in the adenylate energy charge of the most susceptible $L$. obtusata as compared to the most resistant $L$. littorea. It is worth noting that $\mathrm{dG} / \mathrm{d} \xi$ values observed in freshwater-exposed Littorina spp. fall within the range of the minimum levels required for the maintenance of ATPase activities (from $-41 \mathrm{~kJ} \mathrm{~mol}^{-1}$ to $-53 \mathrm{~kJ} \mathrm{~mol}^{-1}$ ) suggested for several invertebrate and vertebrate species (Pörtner 1993; Pörtner et al. 1996). The impaired energy status of the tissue may contribute to limiting survival under conditions of freshwater exposure in the periwinkles.

In conclusion, differential resistance of White Sea periwinkles to freshwater exposure could be explained by different rates of anaerobic metabolism. Osmotic shock due to the gradual dilution of the internal medium seems to be of minor (if any) importance for the survival of the White Sea periwinkles under conditions of hypoosmotic exposure. Minimal resistance of L obtusata to anoxic exposure correlates with a higher anaerobic metabolic rate (reflected in the higher rate of succinate accumulation), faster net ATP breakdown and the inability to reduce ATP turnover rate during prolonged anaerobiosis. This may probably indicate less efficient metabolic arrest under conditions of anoxia in L. obtusata as compared to the other two species. Inability of anaerobic energy production to keep pace with energy demand leads to the observed impairment of energy status which is again most pronounced in the least resistant species L. obtusata. To the best of our knowledge, this is a first study, so far, which clearly indicates the crucial role of energy balance in supporting cell function and integrity under conditions of extreme hypoosmotic stress.

\section{Ecological and evolutionary implications}

Behavioural isolation inside the shell in response to extreme salinities, typical as it is for the marine conchiferous molluscs, appears not to be a specific salinity adaptation. Ability to survive prolonged periods of anoxia caused by such isolation is typical for many intertidal invertebrates and has probably evolved as an adaptation to life in the intertidal zone. Differences in the ability to withstand prolonged anoxia correlate to a certain extent with the ecological peculiarities of the studied species, in particular with their vertical distribution. L. saxatilis which possesses a rather high capability to survive anoxia is a typical eulittoral fringe species which normally inhabits upper intertidal horizons (McMahon 1988, 1990). There the rough 
periwinkles have to face extended periods of limited oxygen availibility at low tide, when they isolate themselves inside the shell not only to escape freshwater exposure during rain or ice melt but also to save water during air exposure. The least anoxia-resistant L. obtusata is a typical mid- and low-shore dweller and experiences comparative short periods of aerial exposure. Moreover, the flat periwinkles maintain activity and thus remain aerobic during most of the air exposure period, as the problem of water conservation is not so acute in this species (McMahon 1988, 1990). Taken together, the peculiarities of vertical distribution and behaviour of L. obtusata results in that much shorter periods of oxygen limitation are normally experienced by this species at low tide.

The most resistant species, L. littorea, seems to be an exception from this pattern. In the White Sea the common periwinkles typically inhabit low intertidal and upper subtidal zones and thus endure the shortest or no exposure to air. It could be assumed that the higher freshwater resistance of L. littorea is an effect of considerably larger size and hence lesser surface/volume ratio resulting in a lower metabolic rate of this species. However, our measurements of routine aerobic metabolic rate suggest that the interspecific differences in metabolic rate are not allometrically related to body size in the studied Littorina spp., at least on a between-species scale. A different explanation arises when the differences in vertical zonation patterns of $L$. littorea in different areas of the distributional range are considered. On North Atlantic coasts, dense populations of L. littorea normally reach middle to high intertidal horizons overlapping to a great extent with both $L$. saxatilis and L. obtusata settlements (Smith and Newell 1955; Newell 1958). In some areas L. littorea was shown to spend 30$90 \%$ of the time in air (Houlihan et al. 1981). Thus this species is probably originally a typical mid- to high-littoral dweller where it may have evolved rather efficient resistance adaptations to survive hypoxia/anoxia periods during air exposure. Shift of the upper limit of L. littorea distribution to the lower intertidal/subtidal zones is probably a response to some specific features (like temperature regime or food abundance) of the White Sea where it settled only recently (ca. 10-11 thousand years ago, after the last glacial period - Fedyakov, personal communication). This view is partially supported by the lower resistance of $L$. littorea to extreme temperatures as compared to L. saxatilis (Zhirmunsky 1969; Golikov and Smirnova 1974).

It is important to emphasise that differential freshwater/anoxia resistance may develop on a very similar physiological and biochemical background which would be expected in closely related species belonging to the same genus. Albeit these differences are to some degree related to the ecological peculiarities of the studied species, some features can be explained only if the evolutionary history and "original" environmental requirements of the species are considered. This demonstrates that physiological mechanisms of fresh- water/anoxia resistance may possess a certain degree of evolutionary conservatism and further emphasises the need to account for evolutionary constraints when discussing physiological adaptations of a species in relation to its ecology.

Acknowledgements Inna Sokolova is grateful to the Otto Kinne Foundation for granting the OKF Fellowship which served for partial financial support of her studies in 1996 and to Alfred-Wegener Institute for Polar and Marine Research (Bremerhaven, Germany) for supporting her work as a guest scientist in 19961998. Field work was in part supported by the Russian Foundation of Basic Research (grant N 98-04-49977 to IS). We are greatly indebted to Dr. Angela Sommer, Mr. Timo Hirse and Mr. Boris Klein for considerable help during the experimental work and to two anonymous reviewers for helpful comments and constructive criticism. All experiments complied with the current laws of the countries (Russia and Germany) where they were performed.

\section{References}

Akberali HB, Mariott KRM, Trueman ER (1977) Calcium utilisation during anaerobiosis induced by osmotic shock in a bivalve mollusc. Nature 266: $852-853$

Atkinson DE (1977) Cellular energy metabolism and its regulation. Academic Press, New York

Avens AC, Sleigh MA (1965) Osmotic balance in gastropod molluscs. I. Some marine and littoral gastropods. Comp Biochem Physiol 16: 121-141

Babkov AI, Lukanin VV (1985) Spring changes of salinity and temperature in surface levels of the White Sea and their influence on distribution of organisms inhabiting intertidal and upper subtidal zones. In: Skarlato OA (ed) Biocenoses of Chupa Inlet and their seasonal dynamics. Nauka, Leningrad 31: 94-98 (in Russian)

Beis I, Newsholme E (1975) The contents of adenine nucleotides, phosphagens and some glycolytic intermediates in resting muscles from vertebrates and invertebrates. Biochem J 152: 23-32

Berger VJ (1980) Euryhalinity of marine molluscs, morpho- functional and evolutionary aspects. Dissertation for a degree of Doctor of Sciences. Leningrad (in Russian)

Berger VJ (1986) Adaptations of marine molluscs to changes of environmental salinity. Nauka, Leningrad (in Russian)

Berger VJ, Kharazova AD (1997) Mechanisms of salinity adaptations in marine molluscs. Hydrobiologia 355: 115-126

Bergmeyer HU (1985) Methods of enzymatic analysis, 3rd edn. Weinheim, vols $1-12$

Byrne RA, McMahon BR (1991) Acid-base and ionic regulation, during and following emersion, in the freshwater bivalve, Anodonta grandis simpsoniana (Bivalvia: Unionidae). Biol Bull 181: 289-297

Churchill TA, Storey KB (1996) Metabolic responses to freezing and anoxia by the periwinkle Littorina littorea. J Therm Biol 21: $57-63$

Fischer JH (1995) Specific detection of nucleotides, creatine phosphate, and their derivatives from tissue samples in a simple, isocratic, recycling, low volume system. In: Liquid Chromatography-gas Chromatography International 8: 254-262

Gäde G, Carlsson KH (1984) Purification and characterisation of octopine dehydrogenase from the marine nemertean Cerebratulus lacteus (Anopla: Heteronemerta): comparison with scallop octopine dehydrogenase. Mar Biol 79: 39-45

Golikov AN, Smirnova NF (1974) Resistance of some gastropod and bivalve species from Chupa Inlet (White Sea) to extreme influences in relation to the problem of evolution of resistance. In: Bykhovsky BE (ed) Seasonal phenomena in the life of White and Barents Seas. Nauka, Leningrad, pp 307-319 
Grieshaber MK, Kreutzer U (1987) Opine formation in marine invertebrates. Zool Beitr 30: 205-229

Grieshaber M, Kronig E, Koormann R (1978) A photometric estimation of phospho-L-arginine, arginine and octopine using homogeneous octopine dehydrogenase isozyme 2 from the squid, Loligo vulgaris Lam. Z Physiol Chem 359: 133-136

Grieshaber MK, Hardewig I, Kreutzer U, Pörtner HO (1994) Physiological and metabolic responses to hypoxia in invertebrates. Rev Physiol Biochem Pharmacol 125: 43-147

Hammen CS (1969) Lactate and succinate oxidoreductases in marine invertebrates. Mar Biol 4: 233-238

Hammen CS, Bullock RC (1991) Opine oxidoreductases in brachiopods, bryozoans, phoronids and molluscs. Biochem Syst Ecol 19: 263-269

Hardewig I, Addink ADF, Grieshaber MK, Pörtner HO, Thillart $G$ van den (1991) Metabolic rates at different oxygen levels determined by direct and indirect calorimetry in the oxyconformer Sipunculus nudus. J Exp Biol 157: 143-160

Hawkins AJS, Hilbish TJ (1992) The costs of cell volume regulation: protein metabolism during hyperosmotic adjustment. J Mar Biol Assoc UK 72: 569-578

Houlihan DF, Innes AJ, Dey DG (1981) The influence of mantle cavity fluid on the aerial oxygen consumption of some intertidal gastropods. J Exp Mar Biol Ecol 49: 57-68

Isani G, Cattani O, Zurzolo M, Pagnucco C, Cortesi P (1995) Energy metabolism of the mussel, Mytilus galloprovincialis, during long-term anoxia. Comp Biochem Physiol 110B: 103-113

Kamp G (1993) Intracellular reactions controlling environmental anaerobiosis in the marine annelid Arenicola marina, a fresh look at old pathways. In: Hochachka PW, Lutz PL, Sick T, Rosental M, Thillart G van den (eds) Surviving hypoxia: mechanisms of control and adaptation. CRC, Boca Raton, pp 5-17

Khlebovich VV (1974) Critical salinity of biological processes. Nauka, Leningrad

Kinne O (1964) Non-genetic adaptation to temperature and salinity. Helgol Wiss Meeresunt 9: 433-458

Kinne O (1971) Salinity. Animals. Invertebrates. In: Kinne O (ed) Marine ecology, London 1 (2): 821-996

Kreutzer U, Siegmund BR, Grieshaber M (1989) Parameters controlling opine formation during muscular activity and environmental hypoxia. J Comp Physiol B 159: 617-628

Kuznetsov VV (1960) The White Sea and biological peculiarities of its flora and fauna. Nauka, Moscow Leningrad (in Russian)

Lim CB, Low WP, Chew SF, Ip YK (1996) Survival of the intertidal pulmonate Onchidium tumidium during short term and long term anoxic stress. Mar Biol 125: 707-713

Livingstone DR (1991) Origins and evolution of pathways of anaerobic metabolism in the animal kingdom. Am Zool 31: $522-534$

Livingstone DR, Zwaan A de, Leopold M, Marteiyn E (1983) Studies on phylogenetic distribution of pyruvate oxidoreductases. Biochem Syst Ecol 11: 415-425

Lockwood APM (1976) Physiological adaptation to life in estuaries. In: Newell RC (ed) Adaptation to environment. Butterworth, London, pp 315-392

Lyzen IM, Sukhotin AA, Sergievsky SO (1990) Influence of the infection by trematode partenites on the water respiration rate of the intertidal mollusk Littorina obtusata. Parazitologiya 26 (6): 521-523 (in Russian with English summary)

Mason AZ, Simkiss K, Ryan KP (1984) The ultrastructural localization of metals in specimens of Littorina littorea collected from clean and polluted sites. J Mar Biol Assoc UK 64: 699-720

McMahon RF (1988) Respiratory response to periodic emergence in intertidal molluscs. Am Zool 28: 97-114

McMahon RF (1990) Thermal tolerance, evaporative water loss, air-water oxygen consumption and zonation of intertidal prosobranchs: a new synthesis. Hydrobiologia 193: 241-260

Michaelidis B, Beis I (1990) Studies on the anaerobic energy metabolism in the foot muscle of marine gastropod Patella caerulea (L.). Comp Biochem Physiol B95: 493-500
Natochin YV, Berger VJ, Khlebovich VV, Lavrova EA, Mikhailova OY (1979) The participation of electrolytes in adaptation mechanisms of intertidal molluscs cells to altered salinity. Comp Biochem Physiol A 63: 115-119

Newell GE (1958) The behaviour of Littorina littorea (L.) under natural conditions and its relation to position on the shore. Mar Biol Assoc UK 37: 229-239

Pörtner HO (1987a) Contributions of anaerobic metabolism to $\mathrm{pH}$ regulation in animal tissues: theory. J Exp Biol 131: 69-87

Pörtner HO (1987b) Anaerobic metabolism and changes in acid-base status: quantitative interelationships and $\mathrm{pH}$ regulation in the marine worm Sipunculus nudus. J Exp Biol 131: 89-105

Pörtner HO (1990) Determination of intracellular buffer values after metabolic inhibition by fluoride and nitrilotriacetic acid. Resp Physiol 81: 275-288

Pörtner HO (1993) Multicompartmental analysis of acid-base and metabolic homeostasis during anaerobiosis: invertebrate and lower vertebrate examples. In: Hochachka PW, Lutz PL, Sick T, Rosental M, Thillart G van den (eds) Surviving hypoxia: mechanisms of control and adaptation. CRC, Boca Raton, pp 139-156

Pörtner HO, Kreutzer U, Siegmund B, Heisler N, Grieshaber MK (1984) Metabolic adaptation of the intertidal worm Sipunculus nudus to functional and environmental hypoxia. Mar Biol 79: 237-247

Pörtner HO, MacLatchy LM, Toews DP (1991) Metabolic responses of the toad Bufo marinus to environmental hypoxia: an analysis of the critical $\mathrm{P}_{\mathrm{O}_{2}}$. Physiol Zool 64: 836-849

Pörtner HO, Finke E, Lee PG (1996) Metabolic and energy correlates of intracellular $\mathrm{pH}$ in progressive fatigue of squid (L. brevis) mantle muscle. Am J Physiol 271: R1404-R1414

Rumsey TJ (1973) Some aspects of osmotic and ionic regulation in Littorina littorea (L.) (Gastropoda, Prosobranchia). Comp Biochem Physiol A 45: 327-344

Siegmund B, Grieshaber MK (1983) Determination of meso-alanopine and D-strombine by high pressure liquid chromatography in extracts from marine invertebrates. Z Physiol Chem 364: $807-812$

Smith JE, Newell GE (1955) The dynamics of the zonation of the common periwinkle [Littorina littorea (L.)] on a stony beach. J Anim Ecol 24: 35-56

Sokal RR, Rohlf FJ (1995) Biometrics. WH Freeman, New York Sokolova IM (1997) Populational aspects of adaptation of the intertidal gastropod molluscs Littorina saxatilis to low salinity. Summary of the dissertation for a degree of candidate of biological sciences. St. Petersburg, pp 1-20 (in Russian)

Sokolova IM, Bock C, Pörtner HO (2000) Resistance to freshwater exposure in White Sea Littorina spp. II: Acid-base regulation. J Comp Physiol B 170: 105-115

Sommer A, Klein B, Pörtner HO (1997) Temperature induced anaerobiosis in two populations of the polychaete worm $\mathrm{Ar}$ enicola marina (L.) J Comp Physiol B 167: 25-35

Storey KB, Storey JM (1990) Metabolic rate depression and biochemical adaptation in anaerobiosis, hibernation and estivation. Quart Rev Biol 65: 145-174

Storey KB, Miller DC, Plaxton WC, Storey JM (1982) Gas liquid chromatography and enzymatic determination of alanopine and strombine in tissues of marine invertebrates. Anal Biochem 125: $50-58$

Storey KB, Kelly DA, Duncan JA, Storey JM (1990) Anaerobiosis and organ specific regulation of glycolysis in a marine whelk. Can J Zool 68: 974-980

Taylor PM, Andrews EB (1988) Osmoregulation in the intertidal gastropod Littorina littorea. J Exp Mar Biol Ecol 122: 35-46

Thillart G van den, van Waarde A (1996) Nuclear magnetic resonance spectroscopy of living systems: applications in comparative physiology. Physiol Rev 76: 799-837

Urbakh VY (1964) Biometrical methods. Nauka, Moscow (in Russian) 
Xomali R, Kaloyaianni M, Beis I (1996) Time course of a tissue specific metabolism of the subtidal gastropod Hexaplex trunculus under anaerobic conditions. Nautilus 110: 1-11

Zhirmunsky AV (1969) Comparative studies of cellular thermoresistance of the White Sea molluscs in relation to species' vertical distribution and the history of fauna formation. Zh obshch Biol 30: 685-702 (in Russian)
Zwaan A de (1983) Carbohydrate catabolism in bivalves. In: Hochachka PV (ed) The Mollusca. Vol. 1. Academic Press, New York, pp 137-175

Zwaan A de, Thillart G van den (1985) Low and high power output modes of anaerobic metabolism: invertebrate and vertebrate strategies. In: Gilles R (ed) Circulation, respiration and metabolism. Springer, Berlin Heidelberg New York, pp 166-192 